\title{
Zastosowanie przedsionkowej płyty policzkowej w leczeniu stłoczeń dolnego łuku zębowego — opis przypadku
}

\author{
Application of vestibular plate in the treatment \\ of crowding in the lower dental arch - case report \\ Katedra i Klinika Ortopedii Szczękowej i Ortodoncji, \\ Uniwersytet Medyczny im. Karola Marcinkowskiego w Poznaniu
}

DOI: http://dx.doi.org/10.20883/df.2020.1

\begin{abstract}
STRESZCZENIE
Płyta Schwarza jest zdejmowanym aparatem ortodontycznym, należącym do grupy aparatów czynnych, powszechnie stosowanym w codziennej praktyce ortodontycznej. W standardowej płytce akryl pokrywa podniebienie oraz część wyrostka zębodołowego od strony jamy ustnej właściwej. Fränkel pomysłodawca wykonania aparatów zwanych regulatorami funkcji, należących do grupy aparatów czynnościowych, jako pierwszy opisał płytę przedsionkową policzkową, której zastosowanie ogranicza się do dolnego łuku zębowego, a cechą charakterystyczną jest umieszczenie akrylu od strony policzkowej, zamiast językowej. Umieszczenie części akrylowej aparatu w przedsionku jamy ustnej powoduje odsunięcie warg i policzków od łuków zębowych, co wyzwala modelujące działanie języka. W pracy przedstawiono przypadek klinicznego zastosowania przedsionkowej płyty policzkowej, będącej modyfikacją płytki Schwarza.
\end{abstract}

Słowa kluczowe: przedsionkowa płyta policzkowa, stłoczenia w dolnym łuku zębowym, aparat czynny, aparat czynnościowy.

\section{ABSTRACT}

The Schwarz plate is a removable orthodontic appliance, belonging to the group of active appliances, commonly used in orthodontic practice. In a standard plate, acrylic covers the palate and part of the alveolar process from the side of proper oral cavity. Fränkel, the originator of the appliances called function regulators, belonging to the group of functional appliances, was the first who describe the vestibule buccal plate, the use of which is limited to the lower dental arch, and the characteristic feature is the placement of acrylic on the cheek side, instead of the linguistic one. Placing the acrylic part of the appliance in the vestibule causes the lips and cheeks to be moved away from the dental arches, which triggers the modeling effect of the tongue. The article presents a case of clinical application of vestibular buccal plate, which is a modification of Schwarz plate.

Keywords: vestibule buccal plate, crowding in the lower dental arch, active appliance, functional appliance.

\section{Wstęp}

Płyta Schwarza jest zdejmowanym aparatem ortodontycznym, należącym do grupy aparatów czynnych, powszechnie stosowanym w codziennej praktyce ortodontycznej. Składa się z akrylowej płyty, klamer, śrub, łuków wargowych, sprężynek oraz elementów dodatkowych umieszczanych w zależności od potrzeby, tj. wyjściowej diagnozy ortodontycznej i efektów, które chcemy przy zastosowaniu tego aparatu uzyskać. Istnieje wiele modyfikacji poszczególnych jego elementów, które odpowiedzialne są za wyzwalanie odmiennych sił prowadzących do korygowania istniejących wad i nieprawidłowości. W standardowej płytce Schwarza akryl pokrywa podniebienie oraz część wyrostka zębodołowego od strony jamy ustnej właściwej [1]. W obrębie żuchwy powoduje to zmniejszenie pojemności jamy ustnej właściwej oraz powierzchni dla języka, co z początku skutkuje zmianami w wymowie, a zasięg akrylu górnej płyty zdarza się, iż wyzwala odruch wymiotny u dzieci wrażliwych [2].

Fränkel, autor regulatorów funkcji należących do grupy aparatów czynnościowych [3, 4, 5], jako pierwszy opisał płytę przedsionkową policzkową, której zastosowanie ogranicza się do dolnego łuku zębowego, a cechą charakterystyczną jest umieszczenie akrylu od strony policzkowej, 
zamiast językowej, a więc odwrotnie jak ma to miejsce w tradycyjnych płytach Schwarza. Z kolei wszystkie elementy druciane, tj. klamry czy łuk wargowy, lokalizują się od strony jamy ustnej właściwej. Ma ona szczególne zastosowanie w przypadkach niekorzystnej konfiguracji anatomicznej części językowej wyrostka zębodołowego, która uniemożliwia zastosowanie klasycznej płyty. Umieszczenie części akrylowej aparatu w przedsionku jamy ustnej powoduje odsunięcie warg i policzków od łuków zębowych, co wyzwala modelujące działanie języka. W piśmiennictwie opisuje się, iż przeniesienie głównej masy aparatu do przedsionka jamy ustnej powoduje łatwiejszą adaptację [6].

\section{Opis przypadku}

7-letnia pacjentka wraz z rodzicami zgłosiła się do Poradni Katedry i Kliniki Ortopedii Szczękowej i Ortodoncji Uniwersytetu Medycznego w Poznaniu z powodu obecnego stłoczenia w obrębie przedniego odcinka dolnego łuku zębowego. W badaniu klinicznym stwierdzono profil twarzy skośny do tyłu, tyłozgryz, zwężenie dolnego łuku zębowego, całkowite zamknięcie szpary po brakującym w łuku zębie 73 oraz brak miejsca na uszeregowanie obecnego stłoczenia. Pacjentkę skierowano na zdjęcie pantomograficzne oraz wykonano pełną dokumentację fotograficzną zewnątrz- i wewnątrzustną (ryciny 1, 2). Zaplanowano wykonanie, wspomnianej we wstępie, przedsionkowej płytki policzkowej opisywanej przez Fränkela, czyli modyfikacji tradycyjnej płytki Schwarza, polegającej na prze- niesieniu akrylowej części płyty aparatu w obręb przedsionka jamy ustnej. Na wysokości brakującego zęba 73 zaprojektowano śrubę odtwarzającą miejsce dla stałego odpowiednika - zęba 33, łuk wargowy klasyczny, wykonany z drutu o grubości 0,8 mm, oraz klamry Adamsa zostały umieszczone od strony jamy ustnej właściwej (rycina 3).

\section{Dyskusja}

W piśmiennictwie spotyka się opisy aparatów charakteryzujących się umieszczeniem części akrylowej w obrębie przedsionka jamy ustnej, wśród nich dominują aparaty czynnościowe. W grupie tej znajdują się przede wszystkim regulatory funkcji Fränkela, które są aparatami czynnościowymi wykorzystującymi część wargową oraz policzkową przedsionka jamy ustnej jako swoje pole działania. Jedną z zalet tego rodzaju aparatu jest zachowanie przestrzeni dla języka, bez zmiany jej wielkości, co analogicznie ma wpływać na zwiększenie komfortu użytkowania tegoż aparatu. Aparat Fränkela może zmienić położenie i nacisk mięśni tworzących zewnętrzny pierścień mięśniowy ust i dzięki temu wpływa na wzrost narządu żucia. Aparat korzystnie oddziałuje na położenie warg i zamykanie szpary ustnej $[6,7,8]$. Analogiczne zalety niesie za sobą wykonana w opisywanym przypadku klinicznym zmodyfikowana płytka przedsionkowa, przeniesienie akrylu do przedsionka jamy ustnej powoduje zachowanie pełnej przestrzeni dla języka, a akryl, odsuwając wargę dolną, zmniejsza jej nacisk na wyrostek zębodołowy, umożliwiając swobodny wzrost doprzedni żuchwy i korekcję ist-

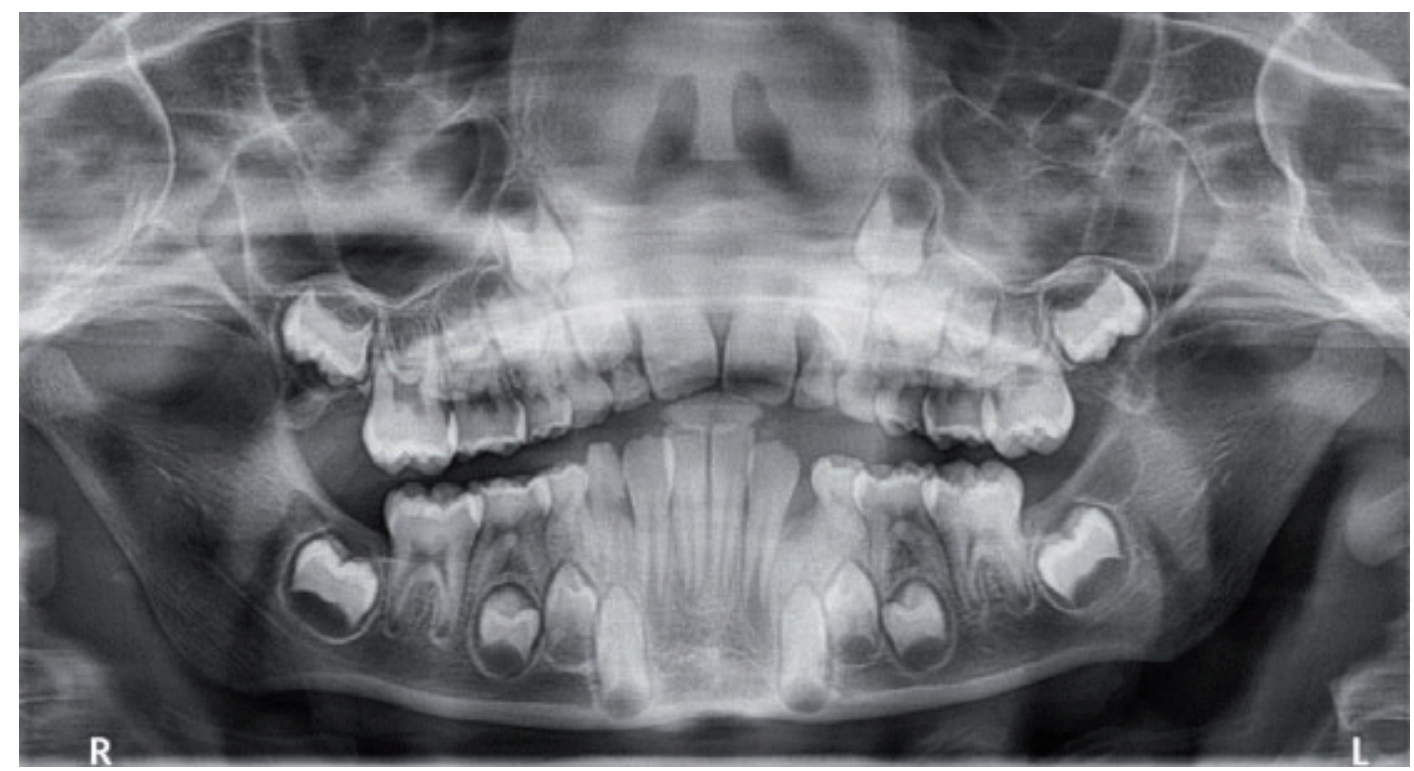

Rycina 1. Dokumentacja radiologiczna pacjentki — zdjęcie pantomograficzne

Figure 1. Radiological documentation of the patient - pantomographic radiograph 

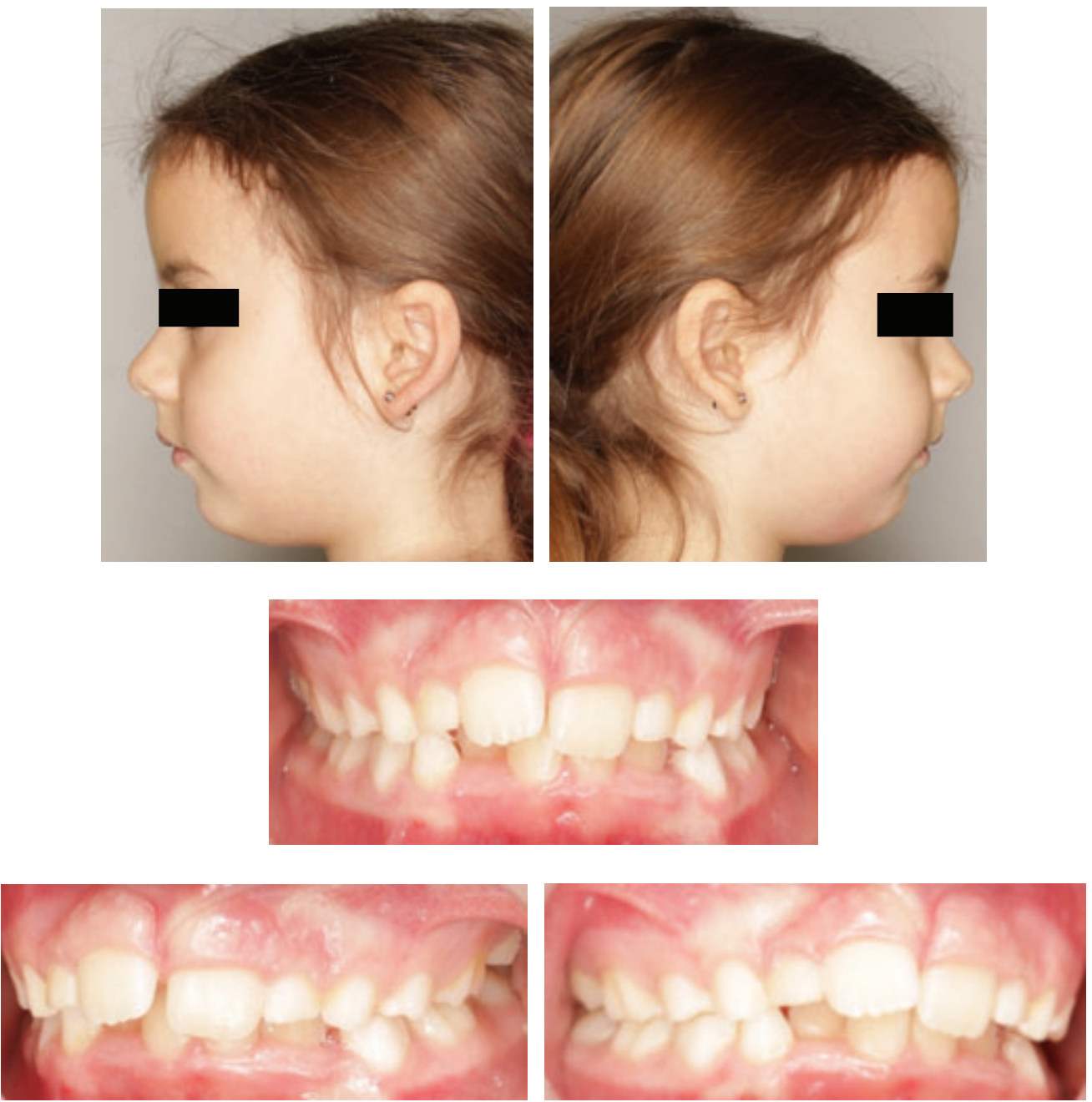

Rycina 2. Fotograficzna dokumentacja medyczna pacjentki

Figure 2. Photographic medical documentation of the patient

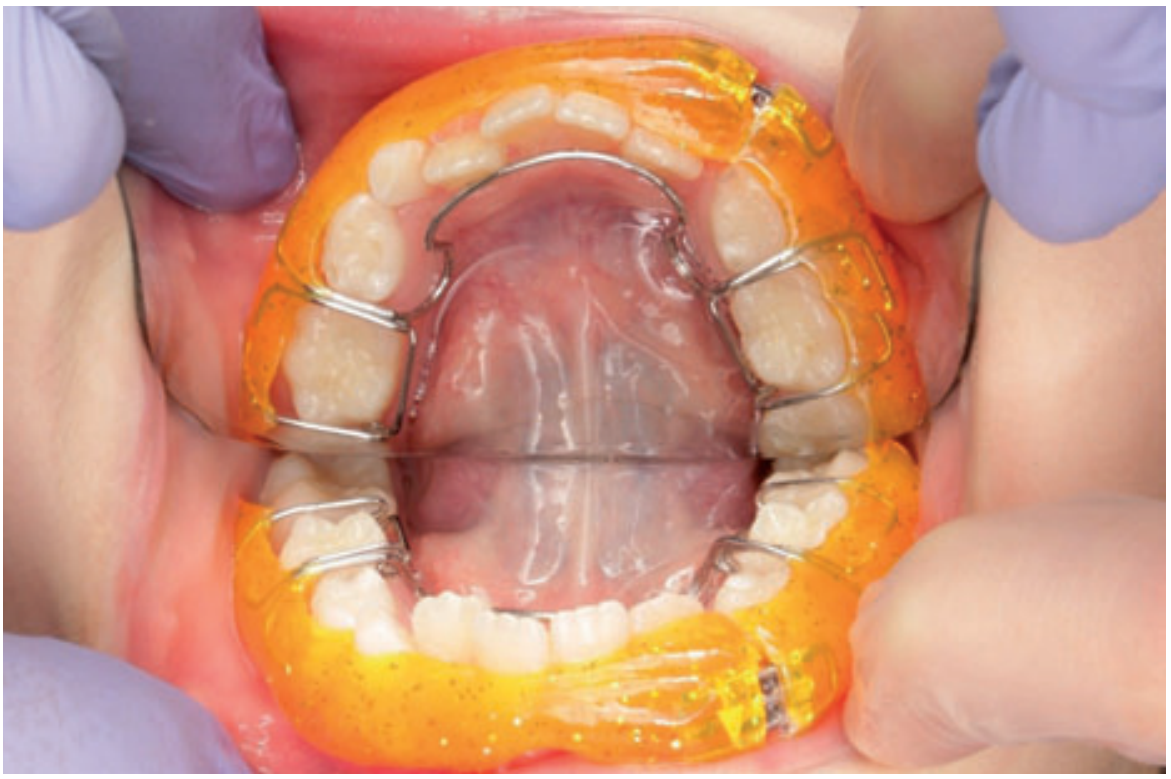

Rycina 3. Wewnątrzustna dokumentacja fotograficzna wykonanej przedsionkowej płyty policzkowej ze śrubą do odtwarzania miejsca po brakującym zębie 73

Figure 3. Intraoral documentation of performed vestibule buccal plate with the screw for reconstruct the space of the missing tooth 73 

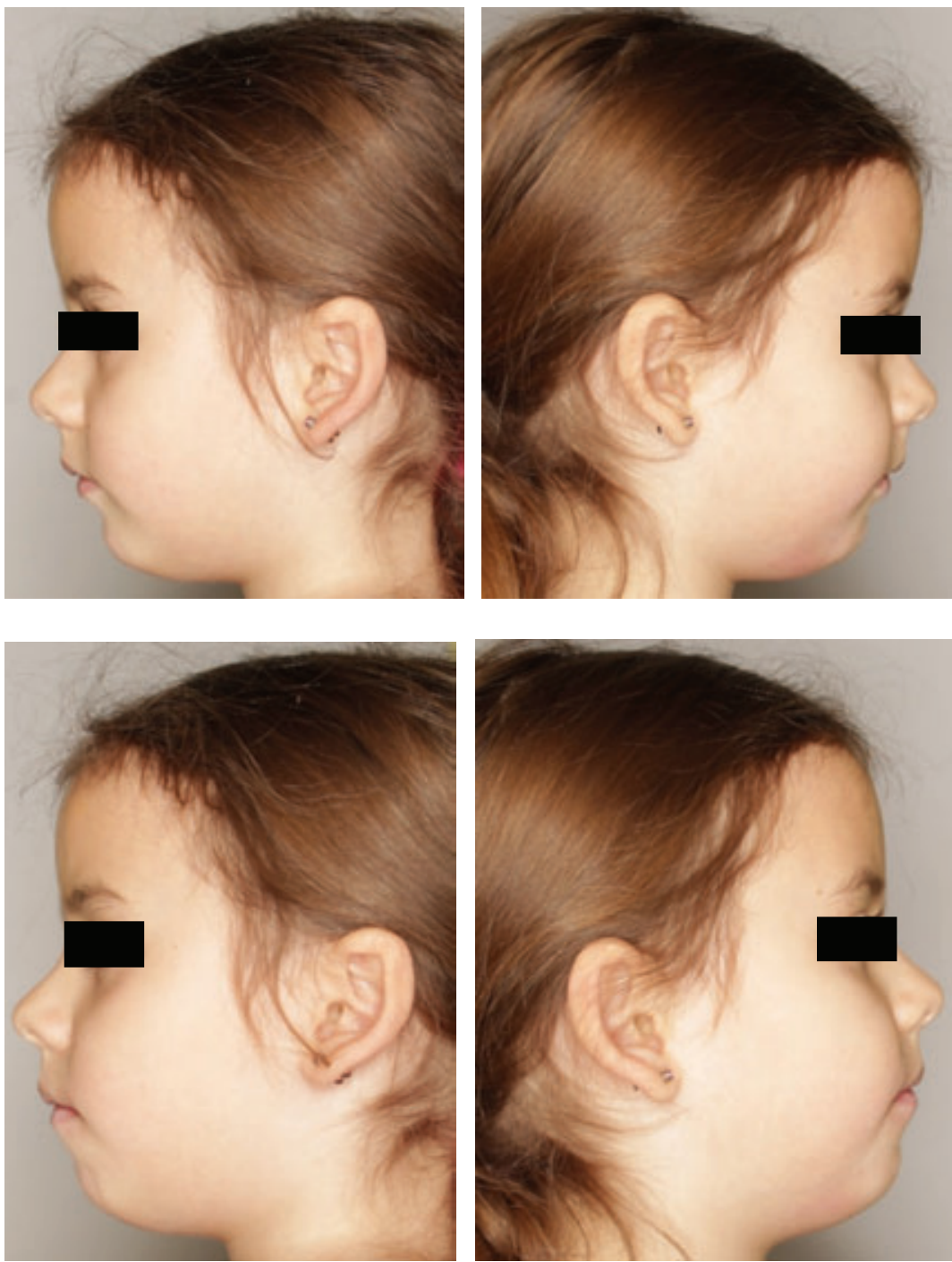

Rycina 4. Porównanie profilu pacjentki bez i z założoną przedsionkową płytą policzkową

Figure 4. Comparison of patient profile without and with vestibule buccal plate

niejącej wady dotylnej. Zmniejszenie nacisku mięśni na część zębodołową żuchwy u opisywanej pacjentki widoczne jest na zdjęciach zewnątrzustnych profilu, na których widać wyraźne odsunięcie wargi dolnej i polepszenie estetyki profilu twarzy, który oceniono w tym przypadku klinicznym jako skośny do tyłu (rycina 4). Należy podkreślić także, iż wykonanie łuku wargowego z grubszego drutu, niż ma to miejsce tradycyjnie, tj. o średnicy $0,8 \mathrm{~mm}$, zwiększa nacisk na stłoczone zęby, generując większą siłę powodującą ich wysunięcie. Obserwuje się szybką adaptację pacjentki do tego rodzaju aparatu. Umieszczenie dodatkowo elementów czynnych, takich jak śruby może wpływać między innymi na rozbudowę i zyskanie potrzebnego miejsca w obrębie łuku zębowego.

\section{Wnioski}

1. Przedsionkowa płyta policzkowa może stanowić alternatywę dla tradycyjnej płytki Schwarza w przypadkach wymagających rozbudowy dolnego łuku zębowego wraz z korektą wady dotylnej.

2. Przedsionkowa płyta policzkowa stanowi alternatywę dla pacjentów wykazujących trudności w adaptacji do tradycyjnej płyty Schwarza wynikających z dyskomfortu towarzyszącemu zmniejszeniu pojemności jamy ustnej właściwej.

\section{Oświadczenia}

Oświadczenie dotyczące konfliktu interesów Autorzy deklarują brak konfliktu interesów w autorstwie oraz publikacji pracy. 
Źródła finansowania

Autorzy deklarują brak źródeł finansowania.

\section{Piśmiennictwo}

[1] Rassumowska-Acquasanta $M$, Tuczyńska A, Kurpik J, Tuczyńska M. Zastosowanie śruby Fischera w aparatach zdejmowanych. Nowoczes Tech Dent. 2020;1:56-62.

[2] Karłowska I. Zarys współczesnej ortodoncji. Wyd. PZWL, Warszawa 2016.

[3] Frankel R. The theoretical concept underlying the treatment with function correctors. Rep Congr Eur Orthod Soc. 1966;42:233-254.

[4] McNamara JA Jr. JCO interviews Dr. James A. McNamara, Jr. on the Frankel appliance. Part 1-Biological basis and appliance design. J Clin Orthod. 1982;16:320-337.

[5] Rushforth CD, Gordon PH, Aird JC. Skeletal and dental changes following the use of the Frankel functional regulator. Br J Orthod. 1999, 26:127-134.

[6] Witt E, Gehrke ME, Komorowska A Wykonywanie aparatów zdejmowanych. Podręcznik dla techników, studentów i lekarzy ortodontów. Wyd. Kwintesencja, Warszawa 1994.
[7] Wirtz U. O-atlas. Atlas techniki ortodontycznej i ortopedii szczękowej. Dentaurum, 2013, 85.

[8] Rakosi T, Graber TM. Leczenie ortodontyczne i ortopedyczne wad zębowo-twarzowych. Leczenie czynnościowe ortodontyczne i ortopedyczne. Wydawnictwo Czelej, Lublin, 2011.

Zaakceptowano do edycji: 2020-07-27

Zaakceptowano do publikacji: 2020-08-10

\author{
Adres do korespondencji: \\ Joanna Kurpik \\ Klinika Ortopedii Szczękowej i Ortodoncji \\ Uniwersytet Medyczny im. Karola Marcinkowskiego \\ w Poznaniu \\ ul. Bukowska 70, 60-812 Poznań \\ e-mail: joanna@kurpik.pl \\ tel.: +48604201503
}

